\title{
Perioperative Management of the Voice in Thyroid Cancer
}

\section{So Yeon Yoon (iD and Hyun Jun Hong}

Department of Otorhinolaryngology-Head \& Neck Surgery, Catholic Kwandong University College of Medicine, International St. Mary's Hospital, Incheon, Korea

갑상선암 수술과 수술 전후 음성관리

윤소연, 홍현준

가톨릭관동대학교 의과대학 국제성모병원 이비인후-두경부외과학교실

Evaluating the patient's voice before thyroidectomy is useful for the purpose of identifying patients with vocal cord paralysis without symptoms, identifying other patient's voice abnormalities, and whether it is related to voice disorders that may occur after surgery. Also voice evaluation after thyroid surgery is helpful in diagnosis, treatment, and rehabilitation and follow-up of voice disorders that occur without clear nerve damage after thyroidectomy. And it is helpful for rapid recovery through active early rehabilitation treatment for patients who complain of speech impairment without paralysis. In particular, neck exercise can improve the adhesion of the surgical site and increase the range of motion of the neck as well as improve subjective neck discomfort. In addition, hearing, voice and breathing functions should be improved, and voice hygiene education and counseling should be provided. Vocal cord injection is the first treatment option for unilateral vocal cord palsy. By establishing a protocol for voice disorders before and after thyroid surgery and providing appropriate treatment, the quality of life of patients can be improved.

Keywords Thyroid cancer; Thyroidectomy; Vocal cord palsy; Speech disorder; Voice therapy.

\section{서 론}

갑상선 절제술 후 음성 변화는 일반적으로 되돌이후두신경(recurrent laryngeal nerve, RLN) 또는 상후두신경(superior laryngeal nerve, SLN) 손상에 기인한다. 그 러나 임상적으로 명백한 신경 손상이나 성대마비가 없는 경우에도 수술 후 음성 변화나 연하 장애를 호소하는 환자들이 간혹 있다. 이런 다양한 증상을 호소하는 경우 갑상선 수술 후 증후군(post thyroidectomy syndrome)으로 정의하고 있다. 갑상선 수술 후 신 경 손상 없는 발성장애의 원인으로는 윤상갑상근(cricothyroid muscle)의 손상, 피대근 (strap muscle)을 비롯한 후두 주변 조직의 손상과 유착, 후두의 혈액순환장애, 기관삽관 시 외상 및 수술에 의한 심리적 변화 등의 가설이 있다. ${ }^{1)}$

수술 후 피할 수 없는 현상을 잘 이해하고 환자들의 회복과 재활을 돕고 수술 전후
Received September 25, 2020

Revised October 6, 2020

Accepted October 12, 2020

\section{Corresponding Author}

Hyun Jun Hong, MD, PhD Department of OtorhinolaryngologyHead \& Neck Surgery,

Catholic Kwandong University

College of Medicine,

International St. Mary's Hospital, 25 Simgok-ro 100beon-gil, Seo-gu, Incheon 22711, Korea

Tel +82-32-290-3878

$\mathrm{Fax}+82-32-290-3879$

E-mail hyunjun.hong@gmail.com

\section{ORCID iDs}

So Yeon Yoon (D) https://orcid.org/0000-0002-7720-6424 Hyun Jun Hong (D)

https://orcid.org/0000-0002-7808-7877

This is an Open Access article distributed under the terms of the Creative Commons Attribution Non-Commercial License (https://creativecommons.org/ licenses/by-nc/4.0) which permits unrestricted non-commercial use, distribution, and reproduction in any medium, provided the original work is properly cited. 
환자 상태를 파악하기 위해 수술 전후 음성정밀 검사의 필요 성이 대두되었다.

\section{본 론}

\section{갑상선 수술 전 음성 검사의 필요성}

최근 들어 갑상선 수술 후뿐만이 아닌 수술 전 음성 검사 의 중요성이 대두되고 있다. ${ }^{2-4)}$ 그 이유는 다음과 같다. 첫 번 째, 수술 전 영상학적 검사에서 종양의 되돌이후두신경 침범 가능성이 높을 경우, 수술 전에 성대마비 여부를 반드시 확 인해야 한다. 두 번째, 수술 전에 음성 증상이 없는 경우에도 성대 움직임의 이상이 많은 환자에서 관찰되고 있다. 한 연구 에 따르면 수술 전 성대마비가 관찰된 환자의 약 $30 \%$ 의 경 우는 음성 증상을 호소하지 않는다는 보고도 있다. ${ }^{3)}$ 만약 수 술 전에 성대 이상을 발견하지 못했다면 갑상선 수술로 인한 합병증으로 오해할 수 있는 여지가 충분하고 이로 인한 법적 인 문제도 초래할 가능성이 있다. 또 다른 이유는 갑상선 수 술이 필요한 환자들의 수술 전에 성대 검사를 해 본 결과 일 반적인 경우보다 높은 비율에서 성대 이상이 발견되고 있기 때문이다. 몇몇의 연구 결과에 따르면 갑상선 수술 전 환자 약 $1 / 3$ 의 경우에서 성대의 이상 소견이 관찰되었다.,5,5) 가장 많은 부분을 차지한 질환은 인후두역류증(laryngopharyngeal reflux disease)이었으며 그 밖에 성대 결절, 성대 폴립, 라인케 부종(Reinke's edema) 등도 관찰되었다.

이와 같이, 수술 전에 환자의 음성을 평가하는 것은 증상이 없는 성대마비 환자의 진단뿐 아니라 환자의 음성 이상을 미 리 발견하는 데 매우 중요한 역할을 하며, 이는 진단이 늦어 져서 치료가 늦어지는 문제를 막고 법적인 문제를 사전에 방 지하는 데 도움을 준다. 그리고 수술 전에 미리 음성 검사를 해두면 수술 후에 발생할 수 있는 음성 변화 그리고 경과에 대해 환자에게 설명을 하는 데 도움이 된다.

의료 환경이 전혀 다른 상황이므로 국내에서 그대로 적용 이 가능한가 하는 의문은 있으나, 최근의 미국 가이드라인에 서도 기준 음성 평가를 모든 환자에서 시행할 것과 후두내시 경 혹은 스트로보스코프(stroboscope)를 이용한 성대움직임 에 대해 기록할 것을 권고하고 있다.) 따라서 수술 전 환자의 목소리 이상 여부를 확인하며, 환자에게 수술 후 발생할 수 있는 신경 손상과 음성 변화 가능성에 대하여 설명하고 수술 후 목소리 변화 혹은 운동 부하(exercise tolerance) 감소, 혹 은 음성 노력(vocal effort)의 증가 등의 현상이 2주 이상 지 속되면 반드시 담당 의료진에 알릴 것과 음성 변화가 발생하 여도 이를 교정할 수 있는 여러 가지 방법이 있다는 사실을 수 술 전에 설명해야 한다.

\section{갑상선 수술 후 음성 검사의 필요성}

갑상선 수술 후 음성 평가는 갑상선 절제술 후 신경 손상 없이도 올 수 있는 음성장애의 관찰 및 술 후 성대마비의 진 단, 추적 관찰을 위하여 필요하다. 되돌이후두신경(RLN) 및 상후두신경(SLN)이 손상받지 않는 단순 갑상선 수술 후에도 많은 환자들이 수술 후 경부 불편감, 감각장애, 고음장애(high pitched disorder), 노래장애(singing difficulty)와 같은 다양 한 음성장애를 호소한다. ${ }^{8)}$ 이를 갑상선 수술 후 증후군이라 고 한다. 수술 부위가 시멘트를 발라놓은 것 같이 단단하고 당기고 조이며, 목소리를 크게 내거나 오래 이야기하기 힘들 며 쉽게 목이 피로해진다고 표현한다. 갑상선 수술 후 음역의 감소(lowered pitch)나 성대 피로, 발화 기본 주파수(speaking fundamental frequency)의 감소, 쉰 목소리, 강도 감소 등 이 밝혀진 바 있다." 갑상선 수술 후 연하 기능에도 변화가 일 어날 수 있는데, 갑상선 엽절제술이나 전절제술을 시행한 환 자의 58\%에서 연하장애가 발견되었다는 보고가 있으며, ${ }^{10)}$ 실 제 연하 손상 지수(swallowing impairment score)를 이용하 여 연하장애 여부를 평가한 연구에서도 양성 종양으로 수술한 이후 연하장애가 20\%에서 발견되었다고 보고한 바 있다. ${ }^{11}$ 갑 상선 수술 직후 기본 주파수(fundamental frequency), 최대 발성 시간(maximal phonation time, MPT), jitter, shimmer, 연성 발성 지표(soft phonation index) 수치가 확연히 감소하 였고, 수술 한 달 후에는 많은 수치가 회복 추세를 보였으나 MPT나 고음역대 주파수의 저하 소견이 여전히 남아 있었 다. ${ }^{12)}$ 따라서 갑상선 환자의 수술 후 주관적, 객관적 불편의 정도의 확인 및 해결을 위해서는 수술 후 음성 검사가 도움 이 된다.

\section{갑상선 수술 후 조기 재활의 필요성}

갑상선 수술 후 증후군의 원인으로는, 후두기관 고착(laryngotracheal fixation), 상후두신경 손상, 림프 부종(lymph edema), 피대근 기능 손상 등이 원인으로 추정되고 있으며, 이 중 후두기관 고착이 가장 중요한 원인으로 추정된다." 수 술 후 후두기관 고착을 감소시키기 위하여 유착이 발생하기 전인 술 후 2주째부터 경부 신전운동(head and neck stretching exercise)을 통하여 증세를 호전시킬 수 있다는 보고가 있 다. ${ }^{13)}$ Takamura 등 ${ }^{13)}$ 의 연구 결과에서 경부 운동을 시행한 환 자군이 그렇지 않은 환자군에 비교하여 경부 불편감의 호전 정도가 수술 후 1 년 경과할 때까지 높다고 발표하였다. Jang 등 ${ }^{14}$ 의 연구 결과에서는 수술 후 다음날부터 경부 운동을 시 작한 환자군에서 수술 후 2주째 주관적인 경부 불편감 또는 객관적인 경부 유착, 경부 운동 범위의 유의한 호전을 관찰할 수 있었지만, 이러한 호전이 수술 후 3 개월이 경과한 이후에 
는 양 군 간의 차이가 없었다. 따라서 조기에 경부 운동을 시 작함으로써 특별한 부작용 없이 수술 후 초기(2주 이내)의 불 편감을 해소하는 데 도움을 준다는 사실을 확인할 수 있었으 며 이는 갑상선절제술 후 환자들의 적극적인 사회생활 복귀 에 도움을 줄 것으로 기대된다. 한편, 평가된 주관적 지표 중 에서 음성장애, 인후두 이물감 및 삼킴장애는 경부 운동의 시 작 시기에 따라 유의한 차이가 관찰되지 않았는데, 이에 대해 서 경부 운동의 효과 및 한계를 정확히 인지하고 향후 환자 교 육에 참고할 필요가 있겠다. ${ }^{14}$ 또한 Jang 등 ${ }^{14}$ 의 연구 결과 조 기에 경부 운동을 시행한 환자들에 있어서 Vancouver Scar Scale을 통해 평가한 상처 형성의 정도가 수술 후 2주 및 3 개 월째 모두에서 대조군과 비교하여 양호한 상태였다. 일반적 으로 조기에 과도한 신전 운동을 시행할 경우 상처 파열의 위 험이 있고 상처 형성에도 악영향을 미칠 수 있다고 생각되는 데, 조기에 경부 운동을 시행한 환자에서 상처 파열은 한 명 도 없었고 상처 형성의 정도 또한 호전된 양상이 관찰되었다. 따라서 목 운동 시작 시기와는 무관하게 수술 후 적극적인 경 부 운동으로 인한 상처 파열 등은 발생하지 않았다는 점을 주목할 필요가 있으며 이를 종합해 보았을 때 조기에 경부 신 전 운동을 시행하더라도 수술 부위 상처 형성에 악영향은 없 었을 것으로 생각된다.

갑상선절제술 후 다음 날부터 시작하는 경부 운동은 수술 상처에 안전하며, 수술 부위 유착의 호전 및 목 운동 범위의 증가뿐만 아니라 주관적 경부 불편감의 호전을 통한 수술 후 초기 삶의 질 개선에 기여할 것으로 기대된다. ${ }^{14)}$

\section{갑상선 수술 후 음성장애 환자의 관리}

갑상선전절제술 후 음성장애의 원인은 되돌이후두신경의 마비가 대표적이다.

일반적으로 되돌이후두신경의 영구적 손상은 일반적으로 $0 \sim 5.2 \%$, 일시적 손상은 0.4 7.2\%에서 발생하는 것으로 알려 져 있다. ${ }^{15-17)}$

일측성 성대마비의 치료 목적은 쉰 목소리의 호전과 흡인 의 방지이다. 치료 방법을 선택할 때 환자의 직업, 환자의 음성 에 대한 요구, 흡인 유무, 성대마비의 유병 기간, 고정된 성대 의 위치, 마비된 성대의 회복 가능성 등이 신중히 고려되어야 한다. 또한 일측의 성대가 마비되었더라도 정상 측의 보상 작 용에 의해 음성 변화가 호전될 수 있으며, 명확한 신경 손상 이 있는 경우가 아니라면 성대 운동성이 회복될 수 있으므 로 6 12개월 정도 추적 관찰이 가능하다. ${ }^{18-20)}$ 치료는 크게 음 성 치료와 수술적 치료로 나눌 수 있다. 음성 치료는 일측성 성대마비 환자에 대해 수술 여부와 관계없이 우선적으로 시행 해야 하며 수술 전후 모두 사용될 수 있다. 음성 치료의 역할
은 성대마비로 인한 부적절한 보상 작용을 제거하고 발성을 도와 효율적인 보상 작용을 향상시키는 데에 있다. 음성치료는 성문폐쇄 및 음성 강도를 향상시킴으로써 성문 틈이 크지 않 은 경우에는 수술과 거의 유사한 효과를 보일 수 있다. ${ }^{21)}$ 또한 중등도 이상의 성문 틈이 있는 환자에게도 수술의 시기를 늦 출 수 있다. ${ }^{22)}$ 하지만 회복 가능성이 없거나, 흡인이 동반되는 경우 조속한 음성 회복이 필요한 경우에는 수술적 치료를 시 행할 수 있으며, 수술적 치료는 크게 성대주입성형술, 갑상성 형술 1형이나 피열연골내전술 같은 후두골격 수술 그리고 후 두신경재지배술로 구분할 수 있으며 음성 치료와 적절히 조합 하여 그 효과를 극대화할 수 있다. ${ }^{23)}$

과거에는 갑상선 수술 후 성대마비가 발생한 경우, 수술 중 에 되돌이후두신경 절단이 확인되는 경우가 아니면, 술 후 6 12개월까지의 성대 기능의 자연 회복을 기다렸다가, 이후에 갑상성형술을 시행하는 것이 원칙이었다. 최근에는 6 12개월 의 기간 동안 환자가 받을 정신적, 사회적 고통을 고려하여 적 극적 초기 치료가 선호되고 있다. 특히 직업적으로 음성을 사 용하거나, 성대마비에 의한 흡인성 폐렴이 발생하는 경우에는 조기 치료가 추천된다. 무엇보다도 조기 성대주입술이 성대 기능 회복에 도움을 주는 것으로 알려져서, 적극적인 조기 치 료를 시행하는 것이 최근에는 주류 의견으로 자리를 잡은 상 태이다. ${ }^{24}$

\section{성대주입술(Injection laryngoplasty)}

성대주입술의 장점으로는 시술이 간단하며, 입원이나 전신 마취가 필요 없어 환자에게 큰 부담을 주지 않고 음성 호전 과 음성과 관련된 삶의 질 향상이 가능하다는 점이다. 시술은 $4 \%$ 리도카인(lidocaine)으로 비강 및 후두를 마취시킨 후 굴곡형 후두내시경으로 성대를 직접 관찰하면서 25 게이지 (gauge) 주사바늘(long disposable needle)을 이용하여 윤상 갑상막을 통하거나(cricothyroid approach), 갑상연골을 딿 거나(transcartilaginous approach), 혹은 갑상설골막을 통 하여(thyrohyoid approach) 성대근(vocalis muscle) 내에 성 대주입물을 주입한다. 갑상선 수술과 연관된 일측성 성대마 비 환자에서 성대주입술이 특히 유용한 이유는 이비인후-두 경부외과의가 직접 수술하고 발생한 성대마비 환자에게 추가 적 경부 절개가 필요한 갑상성형술보다 부담이 덜하기 때문이 다. 2010년 Lee 등 ${ }^{25)}$ 은 갑상선 수술 후 발생한 일시적, 영구적 성대마비 환자 34 명에게 성대주입술 후 음성, 그리고 음성과 관련된 삶의 질이 호전됨을 최초로 보고하였다. 또한 장기 추 적 관찰 결과 성대주입술 후 3년까지 그 효과가 유지됨을 확인 하였다. 일반적 성대주입술에 비하여 갑상선 수술 후 발생한 경우는 주사 부위의 섬유화로 주사 부위의 정확한 위치 확인 
이 어려운 경우가 종종 있어 시술이 만족스럽게 되지 않을 수 있으며 주입 물질은 대부분 영구적 물질이 아니어서 시간이 지남에 따라 흡수되고 필요 시 재주사 혹은 영구 마비 시 외 부 절개를 통한 갑상성형술(thyroplasty) 등이 필요할 수 있 음을 환자에게 고지하여야 한다. ${ }^{26)}$

성대 주입 물질의 선택

현재 대부분의 성대 주입 물질은 주름살 치료를 위한 미용 성형 목적으로 개발된 조직 충전 물질(space filler)의 허가 외 사항(off label)으로 성대에 사용하고 있는 것이 현실이다. 미 국 및 한국 Food and Drug Administration 승인을 받아 성 대에 적용 가능한 유일한 물질은 Radiesse ${ }^{\circledR}$ (Merz Pharma $\mathrm{GmbH} \&$ Co., Frankfurt, Germany)이다. 그 외에도 $\mathrm{Aqu}-$ $\operatorname{amid}^{\circledR}$ (polyacrylamide hydrogel; Ferrosan A/S, Soeborg, Denmark), ArteFill ${ }^{\circledR}$ (Artes Medical, Inc., San Diego, CA, USA), hyaluronic acid derivative(Rofilan; Rofil Medical International, Breda, the Netherland) 등 ${ }^{27}$ 의 성대 주입 물 질들이 술자의 선호도에 따라 사용되고 있다. ${ }^{28)}$ 2015년 Moon 등 29$)$ 은 토끼 성대마비 모델에 calcium hydroxyapatite, polyacrylamide hydrogel, hyaluronic acid derivative를 이용한 6 개월간의 성대 주입 물질 안정성 검증 실험을 한 결과, 기존 의 성대 주입 물질들은 phosphate-buffered saline과 비교했 을 때 경도-중등도(mild to moderate) 이물 반응(foreign body reaction)을 유발하였으나, 이물 육아종(foreign body granuloma)과 같은 심각한 부작용은 보이지 않았다. 따라서 현재 상업적으로 이용 가능한 성대 주입 물질은 큰 부작용 없이 성 대에 사용할 수 있을 것으로 생각된다.

\section{갑상성형술(Thyroplasty) \pm 피열연골내전술(Arytenoid adduction)}

갑상선 수술 후 일측성 영구 성대마비의 표준 치료(gold standard)는 갑상성형술土피열연골내전술이다. 1975년 Isshiki 등이이 갑상성형술을 개발한 이후 가장 많은 임상 결과 가 보고되었고, 안정적인 치료 결과를 얻을 수 있는 장점이 있 다. 하지만 시술 시 신경 손상이 영구적인지 불확실한 경우 6 12 개월을 기다렸다가 시술을 해야 하며, 추가적인 경부 절개 와 동위원소 치료를 받은 환자의 경우, 수술 과정에서 박리 (dissection)가 어려운 단점이 있다. ${ }^{30}$ 일반적으로 후성문 틈 (posterior glottic gap)이 크거나, 마비된 성대 위치가 정상 측 보다 높은 경우(vertical level differences)에는 피열연골내전 술을 동시에 시행하는 것이 추천된다. ${ }^{31)}$ 하지만 현재는 적응 증의 상당 부분이 성대주입술로 대체된 상태이며, 일반적으로 는 발성 시 후성문 틈의 간격이 $1 \mathrm{~mm}$ 이내인 경도 후성문 틈 (mild glottic gap)의 경우에는 성대주입술이, 2 3 mm 이상인 중등도 이상의 후성문 틈(moderate to severe glottic gap)의 경우에는 갑상성형술이 추천되고 있다. ${ }^{24)}$

\section{되돌이후두신경 신경재지배술(RLN reinnervation)}

갑상성형술土피열연골내전술은 정태적 수술(static procedure)로서 시술 후 오랜 시간이 지나면, 탈신경지배 성대 근 육 위축(denervation muscle atrophy)에 의해 음성이 악화되 는 소견이 발생하여 재수술(revision surgery)이 필요한 경우 가 많다. ${ }^{30)}$ 이에 반하여 되돌이후두신경 신경재지배술은 성대 근육량(volume) 및 긴장도(tone)를 유지하여 생리적이면서 도 장기적인 음성 호전이 가능한 장점이 있다. ${ }^{32}$ 하지만 신경 재생이 일어나기 위해서 상당한 시간이 걸리기 때문에 보통 음성 호전을 환자가 느끼기에는 3 6개월간의 기간이 필요하 다는 단점이 있다. ${ }^{33}$ 2014년 Lee 등 ${ }^{34}$ 은 19 명의 일측성 영구 갑상선 성대마비 환자를 대상으로 수술 중 되돌이후두신경 신경재지배술 후 주관적, 객관적 음성 지표가 수술 후 2년째까 지 유의하게 호전됨을 전향적으로 보고하였다. 직접 되돌이후 두신경 신경재지배술은 절단된 신경이 긴장 없이(tension free) 접합이 가능한 경우, 9-0 나일론(nylon)을 사용하여 4 5회 의 신경외막봉합술(epineural suture)을 시행하게 된다. 하지 만 절단 후 결손 부위가 커서 긴장 없는 접합이 불가능한 경우 에는 피대근(strap muscle)으로 가는 목신경고리(ansa cervicalis)와 절단된 되돌이후두신경을 접합시킨다(ansa-RLN reinnervation).

양측성 성대마비는 갑상선 수술 후 발생하는 가장 심각한 합병증으로 약 $1 \%$ 정도에서 발생하는 것으로 알려져 있다. ${ }^{16)}$ 마비된 성대의 위치에 따라 임상적으로 내전형(adductor type), 외전형(abductor type)으로 분류할 수 있다. 내전형 양측성 성대마비의 경우, 수술 후 즉각적인 호흡곤란을 호소 하는 경우가 있으며, 외전형 양측성 성대마비의 경우, 수술 직 후에 호흡곤란과 같은 응급 상황이 없으나, 지속적으로 열려 있는 성대로 인하여 환자는 연하 시 흡인(aspiration), 기식음 (breathy voice)과 같은 음성장애로 고통을 받게 된다. 내전 형 양측 성대마비의 치료 방법으로는 1) 주기적인 관찰(wait \& see), 2) 기관절개술 혹은 기관개창술(tracheotomy or tracheal fenestration), 3) 성대후방절개술 \pm 피열연골부분절제술 (posterior cordotomy \pm medial partial arytenoidectomy), 4) 성대외전술(vocal fold lateralization), 5) 피열연골외전술 (arytenoid abduction)이 있다. 외전형 양측성 성대마비의 치 료 방법으로는 흡인을 호전시키는 연하 훈련(swallowing training)을 시행해 볼 수 있으나, 효과적이지 않아서 장기적으로는 내전형 양측성 성대마비보다 치료가 어려운 것이 현실이다. 


\section{갑상선 수술 후 음성 재활 치료}

수술 후 음성 재활 치료의 주요 목표는 만족할 만한 음성 기 능을 회복하는 것이다. 음성 치료는 보통 여러 번의 회기(session)가 필요하며 음성 질환에 전문화된 음성언어치료사에 의해 이루어져야 한다. 현재까지 다양한 음성 치료 방법들이 발달되어 왔고, 청각, 음성, 체성감각, 근골격 또는 호흡 기능을 향상시키는 직접적 중재 방법과 음성 위생 교육과 상담을 포 함하는 간접적 중재 방법으로 분류된다. ${ }^{35)}$ 음성 치료의 방향 은 위생적, 증상적, 생리적 측면으로 분류할 수 있다. ${ }^{36)}$ 위생적 인 접근은 환자들에게 음성 위생과 충분한 수분 섭취 및 음 성 휴식을 유지하는 등의 좋은 습관을 갖게 교육하는 것이다. 증상적인 접근은 음성의 높낮이, 강도, 질과 같은 발성장애 증상을 해결하는 것이다. 예를 들어 "chant talk," "ear training," "head positioning," "pushing approach" 등의 치료가 포함된다. ${ }^{37)}$ 마지막으로 생리적인 측면은 3가지 접근법 중 가 장 전체론적인 개념으로 음성에 있어 모든 시스템 역할 간의 균형 유지를 강조한다. ${ }^{38)}$ 음성 기능 훈련(vocal function exercise), 공명 음성 치료(resonant voice therapy), 반폐쇄 성도 훈련(semi-occluded vocal tract exercise) 등이 포함된다. ${ }^{39,40)}$

수술 후 음성 치료에서 몇 가지 고려해야 할 것이 있다. 우 선 치료 도중 상처 벌어짐 및 출혈을 피하기 위해 충분히 상 처가 치유된 이후에 음성 치료를 시작해야 한다. ${ }^{41)}$ 또한 수술 시 피대근의 손상 가능성을 고려해야 한다. 흥골설골근(sternohyoid muscle), 흥골갑상근(sternothyroid muscle)이 수축 하면 성문하 압력이 증가하고, 이는 윤상갑상근(cricothyroid muscle)의 수축을 일으킨다. 결과적으로 성대 길이가 늘어나 며 기본 주파수(pitch)와 음성 강도(loudness)를 증가시킨 다. ${ }^{42)}$ 따라서 후두외근에 손상이 있을 경우 쉰 목소리, 피로 감, 고음에 어려움 등을 야기할 수 있으므로, ${ }^{43)}$ 음성 치료에는 근육 이완과 근육 강화 운동이 포함되어야 한다. 또한 전신마 취 수술 시 기관 내 삽관 기왕력에 대한 고려도 필요하다. ${ }^{44}$ 기 관 내 삽관으로 후두점막과 기관에 기계적 자극과 손상이 있
었고 이로 인해 음성 증상이 발생할 수 있기 때문이다. ${ }^{45}$

실제적 예로 가톨릭관동대학교 국제성모병원 갑상선클리 닉-음성클리닉에서 실행하는 진료 과정을 다음과 같이 소개 한다(Fig. 1). 모든 갑상선 수술 환자에 대해서 수술 전 이비인 후-두경부외과 음성클리닉에 내원하여 수술 전 음성 검사를 시행한다. 수술 일주일에서 한 달 후 이비인후과 외래 재내원 하여 후두경으로 성대 상태를 확인 후 수술 전 검사와 동일 한 음성정밀 검사[후두미세진동 검사법(video laryngeal stroboscopy), 음성분석 검사(speech and voice acoustic study), 공기역학 검사(aerodynamic study), 전기성문파형 검사(electroglottography), 음도 검사(voice range profile program)] 를 시행한다. 환자가 음성장애 증상을 호소하는 경우 음성 치 료를 시작하게 된다. 음성 치료의 순서는 첫 번째, 후두 외근 및 목 주변 근육을 마사지하는 후두 마사지; 두 번째, 발성 이전의 준비운동으로 성대가 부드럽게 접촉할 수 있도록 도 와주는 립 트릴(lip trill), 허밍(humming) 기법; 3 번째, 구강 및 비강의 울림을 이용하여 목소리를 증폭시켜 큰 목소리를 낼 수 있도록 해주는 공명 음성 치료; 4번째, 본격적으로 발성 을 시작하여 단어, 문장, 대화 수준에서도 올바르게 발성할 수 있도록 해주는 연성 발성(soft phonation); 5 번째 높은 음 에서도 바르게 발성할 수 있도록 도와주는 성대 기능 훈련의 흐름으로 진행한다. 음성 치료는 환자, 이비인후-두경부외과 의사, 음성언어치료사의 의견들을 조율하여 환자의 음성 기 능 회복에 목표를 두고 진행된다.

\section{결 론}

최근 갑상선암 수술 및 치료 성적에 대한 사회적 관심이 크 게 높아지고 있다. 갑상선암의 치료 목적은 비교적 좋은 예후 를 생각하였을 때 암의 완치 및 재발 방지뿐만이 아니라, 수 술 후 환자들의 조기 사회생활 복귀 및 장기적인 삶의 질에 대한 관리까지 확대되고 있다. 갑상선 수술 전후 음성장애에

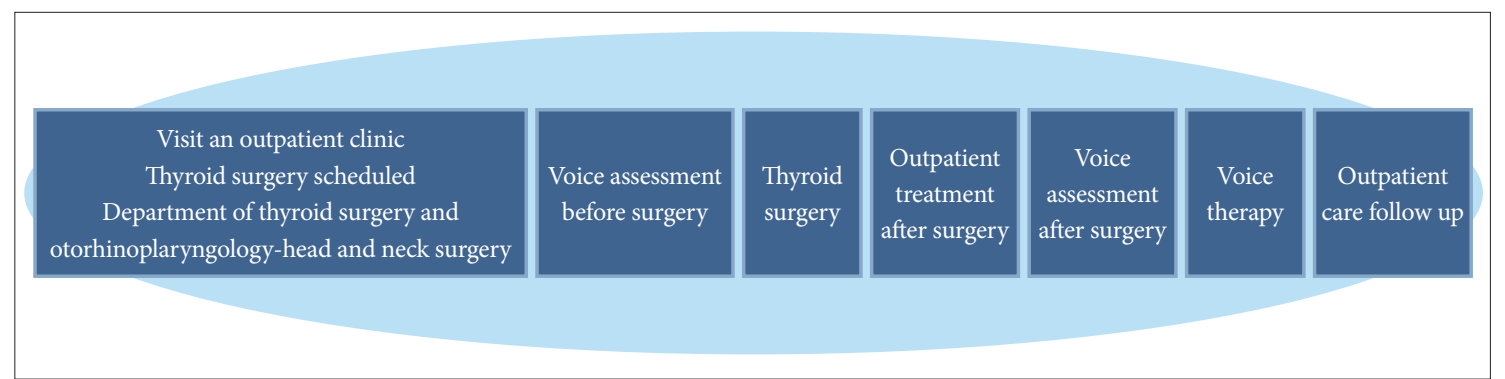

Fig. 1. Process of voice evaluation and treatment in thyroid surgery patients. For all thyroid surgery patients, a preoperative voice assessment is performed by visiting the voice clinic of the otorhinolaryngology-head and neck surgery. One week to one month after surgery, the patient visits the otolaryngology outpatient clinic and perform laryngoscopy and voice tests again. When the patient complains of symptoms of voice abnormalities, voice therapy is started. 
대한 프로토콜을 구축하고 적절한 치료를 제공함으로써, 환 자의 삶의 질 향상에 도움이 될 것으로 사료된다.

중심 단어: 갑상선암, 갑상선절제술, 성대마비, 음성장애, 음 성치료.

\section{Acknowledgments}

Thank you to those who helped me write. Professor Hae Young Son, Department of Thyroid surgery, Catholic Kwandong University College of Medicine, International St. Mary's Hospital, Resident So Yeon Yoon and Yoon Jin Cho, Speech therapist So Ra Lim, Department of Otorhinolaryngology-Head \& Neck Surgery, Catholic Kwandong University College of Medicine, International St. Mary's Hospital.

\section{Conflicts of Interest}

The authors have no financial conflicts of interest.

\section{Authors' Contribution}

Conceptualization: Hyun Jun Hong. Data curation: So Yeon Yoon. Formal analysis: Hyun Jun Hong. Investigation: So Yeon Yoon. Supervision: Hyun Jun Hong. Writing_original draft: So Yeon Yoon. Writing - review \& editing: Hyun Jun Hong. Approval of final manuscript: all authors.

\section{REFERENCES}

1. Hong KH. Post-thyroidectomy syndrome. Korean J Otorhinolaryngol-Head Neck Surg 2014;57(5):297-303.

2. Yeung P, Erskine C, Mathews P, Crowe PJ. Voice changes and thyroid surgery: is pre-operative indirect laryngoscopy necessary? Aust N Z J Surg 1999;69(9):632-4.

3. Farrag TY, Samlan RA, Lin FR, Tufano RP. The utility of evaluating true vocal fold motion before thyroid surgery. Laryngoscope 2006; 116(2):235-8.

4. Bone SL, Vertigan AE, Eisenberg RL. Auditory-perceptual voice characteristics in pre-operative patients undergoing thyroid or parathyroid surgery. Folia Phoniatr Logop 2012;64(2):87-93.

5. Nam IC, Bae JS, Shim MR, Hwang YS, Kim MS, Sun DI. The importance of preoperative laryngeal examination before thyroidectomy and the usefulness of a voice questionnaire in screening. World J Surg 2012;36(2):303-9.

6. Chun BJ, Bae JS, Chae BJ, Hwang YS, Shim MR, Sun DI. Early postoperative vocal function evaluation after thyroidectomy using thyroidectomy related voice questionnaire. World J Surg 2012;36(10): 2503-8.

7. Chandrasekhar SS, Randolph GW, Seidman MD, Rosenfeld RM, Angelos P, Barkmeier-Kraemer J, et al. Clinical practice guideline: improving voice outcomes after thyroid surgery. Otolaryngol Head Neck Surg 2013;148(6 Suppl):S1-37.

8. Sinagra DL, Montesinos MR, Tacchi VA, Moreno JC, Falco JE, Mezzadri NA, et al. Voice changes after thyroidectomy without recurrent laryngeal nerve injury. J Am Coll Surg 2004;199(4):556-60.

9. Myers EN, Hong KH, Kim YK. Phonatory characteristics of patients undergoing thyroidectomy without laryngeal nerve injury. Otolaryngol Head Neck Surg 1997;117(4):399-404.

10. Grover G, Sadler GP, Mihai R. Morbidity after thyroid surgery: patient perspective. Laryngoscope 2013;123(9):2319-23.

11. Scerrino G, Inviati A, Di Giovanni S, Paladino NC, Di Paola V, Lo Re $\mathrm{G}$, et al. Esophageal motility changes after thyroidectomy; possible associations with postoperative voice and swallowing disorders: preliminary results. Otolaryngol Head Neck Surg 2013;148(6):926-32.

12. Kim H, Keum BR, Kim GH, Jeon SS, Kim H, Kim SK, et al. Analysis of voice and swallowing symptoms after thyroidectomy in patients without recurrent laryngeal nerve injury in early postoperative period. J Korean Soc Laryngol Phoniatr Logoped 2016;27(2):108-13.

13. Takamura Y, Miyauchi A, Tomoda C, Uruno T, Ito Y, Miya A, et al. Stretching exercises to reduce symptoms of postoperative neck discomfort after thyroid surgery: prospective randomized study. World J Surg 2005;29(6):775-9.

14. Jang JY, Chang YS, Kim EH, Moon JH, Son YI. Early neck exercises to reduce post-thyroidectomy syndrome after uncomplicated thyroid surgery: a prospective randomized study. J Korean Thyroid Assoc 2014;7(1):70-6.

15. Steurer M, Passler C, Denk DM, Schneider B, Niederle B, Bigenzahn $\mathrm{W}$. Advantages of recurrent laryngeal nerve identification in thyroidectomy and parathyroidectomy and the importance of preoperative and postoperative laryngoscopic examination in more than 1000 nerves at risk. Laryngoscope 2002;112(1):124-33.

16. Barczyński M, Konturek A, Stopa M, Cichoń S, Richter P, Nowak W. Total thyroidectomy for benign thyroid disease: is it really worthwhile? Ann Surg 2011;254(5):724-30.

17. Witt RL. Recurrent laryngeal nerve electrophysiologic monitoring in thyroid surgery: the standard of care? J Voice 2005;19(3):497-500.

18. Jeannon JP, Orabi AA, Bruch GA, Abdalsalam HA, Simo R. Diagnosis of recurrent laryngeal nerve palsy after thyroidectomy: a systematic review. Int J Clin Pract 2009;63(4):624-9.

19. Simpson B, Rosen C. Glottic insufficiency: vocal fold paralysis, paresis, and atrophy. In: Rosen CA, Simpson CB, editors. Operative techniques in laryngology. Berlin: Springer-Verlag;2008. p.29-35.

20. Sridharan SS, Rosen CA, Smith LJ, Young VN, Munin MC. Timing of nimodipine therapy for the treatment of vocal fold paralysis. Laryngoscope 2015;125(1):186-90.

21. Miller S. Voice therapy for vocal fold paralysis. Otolaryngol Clin North Am 2004;37(1):105-19.

22. Isshiki N. Mechanical and dynamic aspects of voice production as related to voice therapy and phonosurgery. J Voice 1998;12(2):125-37.

23. Han JH, Han MW, Nam SY. Management principle of unilateral vocal fold paralysis. J Korean Soc Laryngol Phoniatr Logop 2009;20(2): 110-7.

24. Rosen CA. Phonosurgical vocal fold injection: procedures and materials. Otolaryngol Clin North Am 2000;33(5):1087-96.

25. Lee SW, Kim JW, Chung CH, Mok JO, Shim SS, Koh YW, et al. Utility of injection laryngoplasty in the management of post-thyroidectomy vocal cord paralysis. Thyroid 2010;20(5):513-7.

26. Chung EJ. Voice care for the post-thyroidectomy dysphonia. J Korean Soc Laryngol Phoniatr Logoped 2016;27(1):14-7.

27. Min JY, Hong SD, Kim K, Son YI. Long-term results of Artecoll injection laryngoplasty for patients with unilateral vocal fold motion impairment: safety and clinical efficacy. Arch Otolaryngol Head Neck Surg 2008;134(5):490-6.

28. Park KN, Cho SH, Lee SW. Nationwide multicenter survey for current status of endoscopic thyroidectomy in Korea. Clin Exp Otorhinolaryngol 2015;8(2):149-54.

29. Moon IH, Park KN, Kim HK, Lee S. Utility and safety of commercially available injection laryngoplasty materials in a rabbit model. J Voice 2015;29(1):125-8.

30. Isshiki N, Okamura H, Ishikawa T. Thyroplasty type I (lateral compression) for dysphonia due to vocal cord paralysis or atrophy. Acta Otolaryngol 1975;80(1-6):465-73

31. McCulloch TM, Hoffman HT, Andrews BT, Karnell MP. Arytenoid adduction combined with Gore-Tex medialization thyroplasty. Laryngoscope 2000;110(8):1306-11.

32. Paniello RC, Edgar JD, Kallogjeri D, Piccirillo JF. Medialization versus reinnervation for unilateral vocal fold paralysis: a multicenter randomized clinical trial. Laryngoscope 2011;121(10):2172-9.

33. Aynehchi BB, McCoul ED, Sundaram K. Systematic review of laryngeal reinnervation techniques. Otolaryngol Head Neck Surg 2010; 
143(6):749-59.

34. Lee SW, Park KN, Oh SK, Jung CH, Mok JO, Kim CH. Long-term efficacy of primary intraoperative recurrent laryngeal nerve reinnervation in the management of thyroidectomy-related unilateral vocal fold paralysis. Acta Otolaryngol 2014;134(11):1179-84.

35. Van Stan JH, Roy N, Awan S, Stemple J, Hillman RE. A taxonomy of voice therapy. Am J Speech Lang Pathol 2015;24(2):101-25.

36. Thomas LB, Stemple JC. Voice therapy: does science support the Art? Communicative Disorders Review 2007;1(1):49-77.

37. Boone D, McFarlane SC, Von Berg SL, Zraick RI. The voice and voice therapy. 8th ed. Boston, MA: Allyn \& Bacon;2010.

38. Stemple JC. A holistic approach to voice therapy. Semin Speech Lang 2005;26(2):131-7.

39. Stemple JC, Hapner ER. Voice therapy: clinical case studies. SanDiego, CA: Plural Publishing;2019.

40. Verdolini-Marston K, Burke MK, Lessac A, Glaze L, Caldwell E. Preliminary study of two methods of treatment for laryngeal nodules. J
Voice 1995;9(1):74-85.

41. Kumrow D, Dahlen R. Thyroidectomy: understanding the potential for complications. Medsurg Nurs 2002;11(5):228-35.

42. Hong KH, Ye M, Kim YM, Kevorkian KF, Berke GS. The role of strap muscles in phonation--in vivo canine laryngeal model. J Voice 1997; 11(1):23-32.

43. Henry LR, Solomon NP, Howard R, Gurevich-Uvena J, Horst LB, Coppit $\mathrm{G}$, et al. The functional impact on voice of sternothyroid muscle division during thyroidectomy. Ann Surg Oncol 2008;15(7):2027-33.

44. Kanazawa T, Watanabe Y, Komazawa D, Indo K, Misawa K, Nagatomo T, et al. Phonological outcome of laryngeal framework surgery by different anesthesia protocols: a single-surgeon experience. Acta Otolaryngol 2014;134(2):193-200.

45. Paulauskiene I, Lesinskas E, Petrulionis M. The temporary effect of short-term endotracheal intubation on vocal function. Eur Arch Otorhinolaryngol 2013;270(1):205-10. 